\title{
Anomaly in visual acuity testing in children
}

\author{
R. M. YOUNGSON \\ Eye Department, Cambridge Military Hospital, Aldershot, Hants
}

\section{Quantitative visual acuity assessment in small children}

Quantitative results can be obtained at a much earlier age than is usually thought possible. It is worth-while to make attempts, routinely, from the age of about 2 yrs $6 \mathrm{mths}$, and even earlier in obviously intelligent children. The writer has achieved reliable acuity measurements of one eye at a time at age 2 yrs $2 \mathrm{mths}$ and of binocular acuity at $2 \mathrm{yrs} \mathrm{I} \mathrm{mth}$. Average children succeed by age 2 yrs $10 \mathrm{mths}$ or $3 \mathrm{yrs}$, but slow children may fail to grasp the principle until age 5 or later.

It has been suggested (Keith, Diamond, and Stansfield, 1972) that, in attempting to assess the vision of such very young children, test objects such as letters or symbols must be presented singly, if any success is to be expected. Their method, and also the variation known as the Single E Test, is widely used, but as will be shown this monotype testing may give misleadingly good results in cases of amblyopia compared to linear or multiple test objects

The monotype method is to present the child with a washable plastic board about $15 \times 25 \mathrm{~cm}$. bearing seven letters as shown in the Figure. Each letter is intrinsically symmetrical. The child is seated on mother's lap and mother holds the board in a suitable position in front of him. Usually the child will also grasp the board. He is then shown, one by one, a series of cards (Sheridan Gardiner Test) each bearing one of the letters on the board and is invited, each time, to "Show Mummy which one is the same". Card sizes are selected so that the letters are about the same size as those on the board and difficulty in co-operation may be overcome by a deliberate initial juxtaposition of the relevant letters. The test is, of course, made into a game and is usually much enjoyed. Encouragement and praise is important. When the child has grasped the principle the examiner gradually retreats, while displaying one card at a time, until he is at the marked distance of $6 \mathrm{~m}$. $(20 \mathrm{ft})$; at this stage the child will usually accept occlusion of Address for reprints: Lt-Col. R. M. Youngson, D.O., R.A.M.C., as above. one eye at a time, so that the acuity may be measured in each.

In older, but still illiterate, children, the introductory stages may, of course, be omitted, and a brief

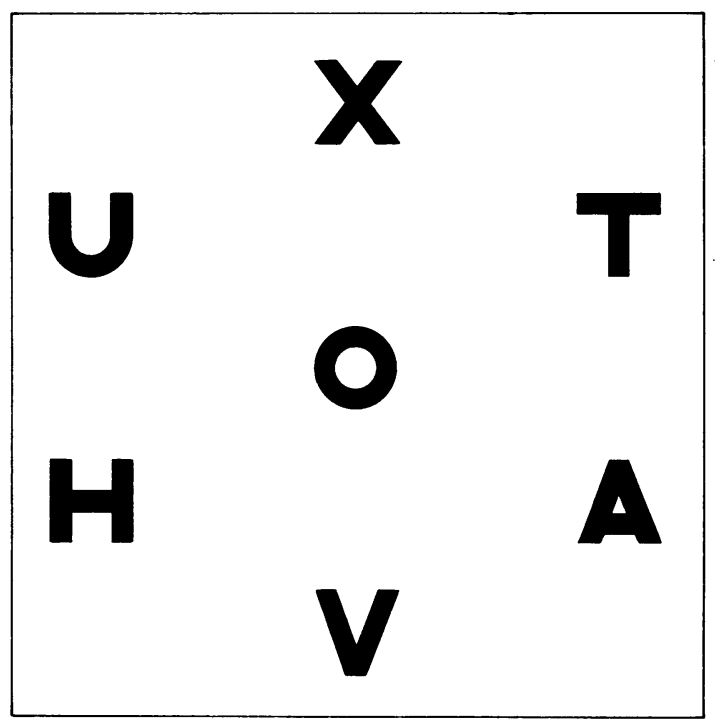

FIGURE Layout of chart used for matching single letters

explanation and demonstration substituted. Encouragement and flattery are still often necessary.

The Sheridan Gardiner cards are provided in convenient spiral-bound book form and the letters correspond in size to those of the Snellen's test cards so that acuity may be recorded in the same way.

\section{Monotype versus linear type}

Considerable personal consulting-room experience of this and other methods of visual acuity testing in children has shown that, in children with normal vision or corrected refractive errors, the results of 
testing with letters shown one at a time correspond with reasonable accuracy to those obtained using standard Snellen's test charts. The differences seldom reach one line of acuity. Shortly after beginning to use Sheridan Gardiner monotypes, however, the writer began to suspect that this was not the case with children suffering from amblyopia. A similar concern had previously been aroused when using the "Single E" orientation test but the matter was not quantitatively pursued. Clinical experience, in the light of this suspicion, soon showed that children with amblyopia could achieve apparent normality when tested with monotypes but at the same time showed a visual acuity varying from two lines worse $(6 / 12)$ to six lines worse $(6 / 60)$ when tested on the Snellen's chart using the same letters and the same "pointing out" method as that employed with the monotype cards. That this was not simply the result of the Snellen's test requiring a greater effort of concentration was demonstrated by the ease with which the $6 / 6$ line was read with the normal eye from the Snellen's chart.
It was further observed that children with severe amblyopia, as determined by monotype testing, who were then energetically treated by effective occlusion of the good eye, would often achieve a rapid improvement in visual acuity, as tested by monotypes, which was not matched by a corresponding improvement on the Snellen's test. In these cases the visual acuity by linear testing (Snellen's) was usually two or three lines worse than by monotype testing.

A paper by Hilton and Stanley (1972), presenting a substantially identical experience, prompted a quantitative investigation of this phenomenon. The results are shown in the Table, which gives the findings in a presenting sample of thirty children with uniocular amblyopia, mostly due to squint, and shows indisputably that reliance on monotype testing, in such cases, can give dangerously optimistic results. Cases I, 5, 15, 16, 18, and 25 are particularly significant, as each demonstrates apparently fully normal visual acuity by monotype testing in an eye which, on linear testing, is found to be significantly or severely

Table Results of testing by monotype and linear type in 30 amblyopic children

\begin{tabular}{|c|c|c|c|c|c|c|c|c|}
\hline \multirow{2}{*}{ Case no. } & \multirow{2}{*}{$\begin{array}{l}\text { Age } \\
\text { (yrs) }\end{array}$} & \multirow{2}{*}{$\begin{array}{l}\text { Cause of } \\
\text { amblyopia }\end{array}$} & \multirow{2}{*}{$\begin{array}{l}\text { Eye } \\
\text { affected }\end{array}$} & \multicolumn{2}{|l|}{ Right eye } & \multicolumn{2}{|l|}{ Left eye } & \multirow{2}{*}{$\begin{array}{l}\text { Difference } \\
\text { expressed as } \\
\text { no. of lines } \\
\text { on Snellen } \\
\text { chart }\end{array}$} \\
\hline & & & & Monotype & Linear & Monotype & Linear & \\
\hline I & 13 & Squint & $\mathrm{L}$ & $6 / 6$ & $6 / 6$ & $6 / 6$ & $6 / 24$ & 4 \\
\hline 2 & $\ddot{5}$ & Squint & $\mathbf{L}$ & $6 / 9$ & $6 / 12$ & $6 / 9$ & $6 / 60$ & 5 \\
\hline 3 & 8 & Astigmatism & $\mathbf{R}$ & $6 / 9$ & $6 / 18$ & $6 / 9$ & $6 / 9$ & 2 \\
\hline 4 & 6 & Squint & $\mathbf{R}$ & $6 / 9$ & $6 / 18$ & $6 / 6$ & $6 / 12$ & 2 \\
\hline 5 & 8 & Squint & $\mathbf{L}$ & $6 / 6$ & $6 / 6$ & $6 / 6$ & $6 / 12$ & 2 \\
\hline 6 & 5 & Squint & $\mathbf{R}$ & $6 / 9$ & $6 / 18$ & $6 / 6$ & $6 / 9$ & 2 \\
\hline 7 & 6 & Squint & $\mathrm{L}$ & $6 / 6$ & $6 / 6$ & $6 / 9$ & $6 / 18$ & 2 \\
\hline 8 & 3 & Squint & $\mathbf{L}$ & $6 / 6$ & $6 / 9$ & $6 / 6$ & $6 / 36$ & 5 \\
\hline 9 & 7 & Squint & $\mathbf{L}$ & $6 / 9$ & $6 / 9$ & $6 / 12$ & $6 / 24$ & 2 \\
\hline 10 & 3 & Squint & $\mathbf{R}$ & $6 / 6$ & $6 / 18$ & $6 / 6$ & - & 3 \\
\hline I I & 5 & Squint & $\mathbf{L}$ & $6 / 9$ & - & $6 / 9$ & $6 / 60$ & 5 \\
\hline 12 & 7 & Squint & $\mathbf{R}$ & $6 / 6$ & $6 / 24$ & $6 / 6$ & $6 / 6$ & 4 \\
\hline 13 & 6 & Squint & $\mathrm{L}$ & $6 / 6$ & $6 / 9$ & $6 / 6$ & $6 / 18$ & 3 \\
\hline 14 & 6 & Squint & $\mathbf{R}$ & $6 / 6$ & $6 / 18$ & $6 / 9$ & - & 3 \\
\hline 15 & 6 & Squint & $\mathrm{L}$ & $6 / 6$ & $6 / 6$ & $6 / 6$ & $6 / 18$ & 3 \\
\hline 16 & 7 & Squint & $\mathbf{R}$ & $6 / 6$ & $6 / 24$ & $6 / 6$ & $6 / 6$ & 4 \\
\hline 17 & 6 & Squint & $\mathbf{L}$ & $6 / 6$ & $6 / 6$ & $6 / 18$ & $6 / 60$ & $\begin{array}{l}\mathbf{4} \\
3\end{array}$ \\
\hline 18 & 5 & Squint & $\mathbf{L}$ & $6 / 6$ & $6 / 6$ & $6 / 6$ & $6 / 60$ & 6 \\
\hline 19 & 4 & Squint & $\bar{L}$ & $6 / 6$ & - & $6 / 6$ & $6 / 18$ & 3 \\
\hline 20 & 4 & Squint & $\mathbf{L}$ & $6 / 6$ & $6 / 9$ & $6 / 6$ & $6 / 12$ & 2 \\
\hline 21 & 4 & Squint & $\bar{L}$ & $6 / 6$ & $6 / 18$ & $6 / 6$ & $6 / 18$ & 4 \\
\hline 22 & 5 & Anisometropia & & $6 / 9$ & $6 / 24$ & $6 / 6$ & $6 / 6$ & 3 \\
\hline 23 & 5 & Squint & $\mathbf{L}$ & $6 / 6$ & $6 / 9$ & $6 / 6$ & $6 / 18$ & 3 \\
\hline 24 & 4 & Squint & $\mathbf{L}$ & $6 / 6$ & $6 / 6$ & $6 / 6$ & $6 / 9$ & I \\
\hline 25 & 9 & Squint & $\mathbf{L}$ & $6 / 6$ & $6 / 6$ & $6 / 6$ & $6 / 36$ & 5 \\
\hline 26 & 5 & Squint & $\mathbf{R}$ & $6 / 12$ & $6 / 24$ & $6 / 6$ & $6 / 9$ & 2 \\
\hline 27 & 4 & Astigmatism & L & Cataract $R$ & & $6 / 6$ & $6 / 60$ & 6 \\
\hline 28 & 4 & Squint & $\overline{\mathbf{R}}$ & $6 / 9$ & $6 / 24$ & $6 / 9$ & $6 / 24$ & 4 \\
\hline 29 & 5 & Squint & $\mathbf{L}$ & $6 / 6$ & $6 / 6$ & $6 / 12$ & $6 / 18$ & $\begin{array}{l}\mathbf{4} \\
\mathbf{I}\end{array}$ \\
\hline 30 & 7 & Squint & $\bar{L}$ & $6 / 6$ & - & $6 / 6$ & $6 / 9$ & $\mathbf{I}$ \\
\hline
\end{tabular}

Readings for affected eye shown in bold type 
amblyopic. In addition, these cases bring out the fact that the child concerned is able correctly to make out the 6/6 linear types with the normal eye, thus showing that the poor relative performance of the amblyopic eye is not the result of the greater difficulty of the test.

The Table also shows the difference in the result obtained in the amblyopic eye expressed in terms of the number of lines of Snellen's chart by which the monotype test exceeds the result on linear testing. Note that in only three cases (ro per cent.) is the difference as little as one line (Cases 24, 29, 30). The average difference for the series is just over three lines. In other words, an amblyopic eye tested with monotypes and giving an apparent visual acuity of $6 / 6$ is more than likely to have a true acuity of no better than $6 / 18$.

\section{Discussion}

The explanation of this effect (which has been described as the "crowding phenomenon") is by no means simple. Cüppers (1956) suggested that it resulted from blurring arising from simultaneous abnormal and normal localization in patients who had had occlusive treatment. It has also been suggested (Burian, 1969) that, since fixation nystagmus is grosser in amblyopia than in the normal, the image of the letter being fixed might be smudged by those adjacent to it. Miller (1954, 1955) put forward the theory that amblyopic eyes showed a loss of lateral inhibition and this explanation was supported by the work of Flom, Weymouth, and Kahneman (1963). It is, of course, well known that the recognition of form is influenced by adjacent contours, and Flom and his colleagues have shown that the effect of contour interaction on visual resolution is much greater in amblyopic than in normal eyes.

It is remarkable that this phenomenon should not have been widely recognized. Casellato (I97I) advocated, as an international standard, a method of visual acuity testing using single letters which could be rotated into different positions. Such a method may be relied upon to conceal, rather than to demonstrate, amblyopia. Again, in an account of a comprehensive study of visual parameters in pre-school children, Amigo (1973) based all visual acuity findings on the results of the Single E orientation test. Personal experience of the Single $\mathrm{E}$ test, in many amblyopic patients, has shown that this method of monotype testing is just as misleading as the Sheridan Gardiner test. Hyams and Neumann (1972) have advocated a "picture cube" with one drawing on each face, for vision screening in pre-school children. Keith and others (1972), whose work has already been mentioned, in a comparative trial of various methods of visual acuity testing in children, found linear methods to give results which were so poor that they were eliminated from the investigation. They therefore confined their work to trials of various kinds of monotypes and concluded that the Sheridan Gardiner method was the best.

Such findings and recommendations tend to lend authority to the view that monotype testing is a direct substitute for linear testing. Undeniably, the monotype method is of considerable value in assessing vision in very young children provided its shortcomings are appreciated. Great patience is needed, but it is not as difficult as is implied to progress from a monotype test, which was thoroughly enjoyed by the child, to one in which letters indicated on a Snellen's chart could be identified by the illiterate child on the Sheridan Gardiner board. This is a true linear test, comparable to reading the letters, and one can almost always succeed in this with children in the third year of life.

\section{Conclusion}

Methods of visual acuity testing in children which employ symbols presented singly, while useful as a means of rough estimation or coarse screening, are no basis for a final assessment or for checking the results of treating amblyopia.

\section{Summary}

A popular and widely used method of visual acuity testing of young children is criticized on the grounds that it often fails to elicit amblyopia. The results obtained when the visual acuity of thirty amblyopic children was tested by different methods show that monotype testing gives an apparent acuity averaging three grades better than those derived from the standard Snellen's test.

\section{References}

AMIGo, G. (1973) Brit. F. Ophthal., 57, 125

BURIAN, H. м. (1969) Amer. F. Ophthal., 67, I

CASEllato, L. (1971) Brit. F. Ophthal., 55, 44

cüPPERS, c. (1956) Klin. Mbl. Augenheilk., 129, 579

flom, м. C., Weymouth, f. W., and kahneman, D. (1963) F. opt. Soc. Amer., 53, 1026

hilton, A. F., and Stanley, J. c. (1972) Brit. F. Ophthal., 56, I 35

HYAMS, s. W., and NEUMANN, E. (1972) Ibid., 56, 572

KEITH, C. G., DIAMOND, Z., and STANSFIELD, A. (1972) Ibid., 56, 827

MILlER, E. F. (1954) Amer. F. Optom., 3I, 6 I 5

(1955) Ibid., 32, 10 